\title{
Pharmacological and Non-pharmacological Treatments for Stroke Prevention in Patients with Atrial Fibrillation
}

\author{
Laura Ueberham · Nikolaos Dagres · Tatjana S. Potpara · Andreas Bollmann • \\ Gerhard Hindricks
}

Received: July 12, 2017 / Published online: September 27, 2017

(C) The Author(s) 2017. This article is an open access publication

\begin{abstract}
Atrial fibrillation (AF) is associated with significant risk of stroke and other thromboembolic events, which can be effectively prevented using oral anticoagulation (OAC) with either vitamin $\mathrm{K}$ antagonists (VKAs) or non-VKA oral anticoagulants (NOACs) dabigatran, rivaroxaban, apixaban, or edoxaban. Until recently, VKAs were the only available means for OAC treatment. NOACs had similar efficacy and were safer than or as safe as warfarin with respect to reduced rates of hemorrhagic stroke or other intracranial bleeding in the respective pivotal randomized clinical trials (RCTs) of stroke prevention in non-valvular AF patients. Increasing "real-world" evidence on NOACs broadly confirms the results of the RCTs. However, individual patient characteristics including renal function, age, or prior bleeding should be taken into account when choosing the OAC with best
\end{abstract}

Enhanced content To view enhanced content for this article go to http://www.medengine.com/Redeem/ 523CF06042E4AA13.

L. Ueberham $(\bowtie) \cdot$ N. Dagres · A. Bollmann ·

G. Hindricks

Department of Electrophysiology, HELIOS Heart

Center Leipzig, Leipzig, Germany

e-mail: uelaura@web.de

T. S. Potpara

Cardiology Clinic, Clinical Center of Serbia, School

of Medicine, University of Belgrade, Belgrade, Serbia risk-benefit profile. In patients ineligible for OACs, surgical or interventional stroke prevention strategies should be considered. In patients undergoing cardiac surgery for other reasons, the left atrial appendage excision, ligation, or amputation may be the best option. Importantly, residual stumps or insufficient ligation may result in even higher stroke risk than without intervention. Percutaneous left atrial appendage occlusion, although requiring minimally invasive access, failed to demonstrate reduced ischemic stroke events compared to warfarin. In this review article, we summarize current treatment options and discuss the strengths and major limitations of the therapies for stroke risk reduction in patients with AF.

Keywords: Atrial fibrillation; Left atrial appendage ligation and closure; Oral anticoagulation; Percutaneous left atrial appendage occlusion; Stroke, thromboembolic events; Vitamin K antagonists; Non-vitamin K antagonist

\section{INTRODUCTION}

Atrial fibrillation (AF) is the most common sustained cardiac arrhythmia in adults, representing a substantial health care burden [1]. The arrhythmia is associated not only with impaired quality of life and frequent hospitalizations but 
also a higher risk of stroke, other thromboembolic events, and increased mortality $[2,3]$. A fibrillating left atrium (LA) meets all the requirements for thrombus formation of Virchow's triad, especially in the LA appendage (LAA) [4]. The risk of stroke in AF patients varies according to the individual risk profile, but the overall ischemic stroke rate without oral anticoagulation (OAC) is approximately 3.20 per 100 person-years [5]. Patients with AF-related strokes have worse outcomes compared to other stroke etiologies [6]. Individual stroke risk assessment and the use of optimal stroke prevention strategy are mandated in all $\mathrm{AF}$ patients. The use of OAC should be considered first or, if contraindications are present, an interventional or surgical LAA occlusion or amputation could be considered.

In this review we outline contemporary pharmacological and non-pharmacological treatments for stroke prevention in AF patients.

This article is based on previously conducted studies and does not involve any new studies of human or animal subjects performed by any of the authors.

\section{THROMBUS FORMATION IN AF}

More than $90 \%$ of LA thrombi in nonrheumatic $\mathrm{AF}$ are formed in the LAA [7]. Representing a remnant of the original embryonic LA, the LAA is not only a simple attachment but also shows a complex sequence of filling and emptying with substantial volume changes over the cardiac cycle [8]. Irregular electrical activation of the LA and the LAA during AF facilitates thrombus formation due to abnormal blood flow. Abundance of LAA morphologies has been described recently $[8,9]$ with a simplified classification of four LAA types with the descriptive names cactus, windsock, chicken wing, and cauliflower [10]. The different LAA morphologies are currently evaluated with respect to the specific morphology-associated risk for thrombus formation, and the results published so far are inconsistent regarding the "high-risk" morphology [10-12].

Endothelial and blood component-specific factors promoting blood clot formation in $\mathrm{AF}$, e.g., endothelial dysfunction, alterations in coagulation, inflammation, and hemoconcentration, have been described in detail elsewhere [4]. Although the association of AF and ischemic stroke depending on the individual stroke risk factors has been clearly established, studies in patients with cardiac implantable devices and hence accurate AF detection showed a surprising lack of clear temporal relation between AF episodes and thromboembolic events [13, 14], which is currently under intensive investigation [15].

\section{ORAL ANTICOAGULANT DRUGS FOR STROKE PREVENTION IN AF}

The use of OAC [either vitamin $\mathrm{K}$ antagonists (VKAs) or non-vitamin $\mathrm{K}$ oral anticoagulants (NOACs)] should be considered in all AF patients at risk of stroke in the absence of contraindications. The risk of AF-related stroke is commonly assessed using the $\mathrm{CHA}_{2} \mathrm{DS}_{2}$-VASc [congestive heart failure, hypertension, age $(\geq 75)$, diabetes mellitus, stroke history or TIA, vascular disease, age 65-74, sex category female] score, which is recommended by international AF guidelines [16-19]. Recently, a concern has been raised about the necessity of OAC use for stroke prevention in AF patients with a single additional $\mathrm{CHA}_{2} \mathrm{DS}_{2}$-VASc stroke risk factor due to low observed stroke rates in a few AF cohorts [20]. However, even though not all risk factors in the $\mathrm{CHA}_{2} \mathrm{DS}_{2}$-VASc score carry an equal risk, the other study demonstrated a higher observed stroke risk in AF patients with a single additional risk factor $[20,21]$. In addition, other studies clearly showed that the use of OAC in AF patients with a single additional stroke risk factor was associated with reduced risk of stroke and mortality [22, 23]. Consequently, all AF patients with one or more additional stroke risk factors (i.e., a $\mathrm{CHA}_{2} \mathrm{DS}_{2}$-VASc score of 1 in men and 2 in women) should be considered for OAC therapy. Additional stroke risk factors not covered by the $\mathrm{CHA}_{2} \mathrm{DS}_{2}$-VASc score, such as the LAA morphology [10], LA enlargement [24], African ethnicity [25], renal function [26], and other factors [27-29], are currently under investigation. Besides, evolving ablation 
strategies including electrical isolation of the LAA further complicate stroke risk assessment. Whether electrical LAA isolation leads to higher stroke risk because of reduced LAA blood flow velocity is subject to ongoing discussions [30-32].

A drawback of OAC use is the risk of OAC-related bleeding. Of various proposed tools for bleeding risk assessment, the HAS-BLED [uncontrolled hypertension, advanced renal or liver disease, a history of stroke, previous bleeding, labile international normalized ratio (INR), age $>65$ years, concomitant drugs predisposing to bleeding (aspirin or nonsteroidal anti-inflammatory drugs, excessive alcohol use)] score provides well-balanced simplicity and predictive ability for bleeding events and is most commonly used [33]. Individualized and balanced risk stratification remains the most challenging task. In clinical practice and outside clinical trials it is especially the patient with "special" risk profile due to, e.g., chronic kidney disease on dialysis, prior ischemic stroke or prior intracranial bleeding, malignancies, special genetic features, and substantial co-medication who demands attention [34].

\section{Vitamin K Antagonists}

Since the isolation of 4-hydroxycoumarin in 1940 by Link and colleagues [35], VKAs have been proven to be effective and safe in the prevention of AF-related thromboembolic complications, and large randomized controlled trials (RCT) on VKA therapy reported a two-third risk reduction in strokes compared to placebo [36]. However, it is important to note that the overall efficacy and safety of VKAs are highly dependent on the quality of VKA management.

As VKAs disable the "regeneration" of vitamin $K$ within the vitamin $K$ epoxide cycle via inhibition of the vitamin $\mathrm{K}$ epoxide reductase enzyme and thus interrupt the carboxylation of inactive blood coagulation factors, the effect of VKAs does not occur immediately but after $48-72 \mathrm{~h}$, because coagulation factors that are already carboxylated and active still work. Furthermore, at the beginning of VKA therapy a transient hypercoagulable state can occur as a result of the decrease of baseline protein $C$ and protein $\mathrm{S}$ levels before decrease of vitamin K-dependent clotting factor levels respectively [37]. Besides the complex initiation phase of VKA therapy, which closely depends on liver function, the inhibition of the vitamin $\mathrm{K}$ epoxide reductase enzyme can be compensated with higher concentrations of vitamin $\mathrm{K}$ thus influencing the dose-response relationship. It seems that a predominantly higher vitamin $\mathrm{K}$ intake at a day-by-day level leads to greater body stores and thus a stronger resilience when variations in vitamin $\mathrm{K}$ intake occur. Apparently, stable dietary habits support stable INR values, but large-scale prospective trials are lacking [38, 39]. On the other hand, it is thus possible to initiate reversal or antagonization of VKAs in case of exaggerated anticoagulation states using vitamin $\mathrm{K}$ compounds.

Regular monitoring of the INR, a measure of VKA anticoagulation intensity, is mandatory because of the narrow therapeutic window of VKAs. Since a single INR value is not a reliable indicator of the quality of VKA anticoagulation over a time period, the time in therapeutic range (TTR) is used as a measure of the quality of VKA management. Unfortunately, the target TTR values of at least $65-70 \%$ are often difficult to maintain in routine clinical practice. A recently published summary of various meta-analyses showed that the TTR is located most of the time below the target value of $65 \%$ in patients on VKAs [40]. Evidently, both the efficacy in stroke prevention and safety concerning the VKA-related bleeding risk are strongly influenced by the achieved TTR

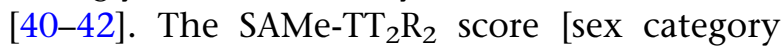
female, age $<60$ years, medical history (more than two comorbidities), treatment (interacting drugs, e.g., amiodarone for rhythm control), tobacco use, race (non-Caucasian)] has been developed as a simple tool to identify patients at higher risk for poor TTR control [43].

The anticoagulant effect of VKAs is also influenced by genetic factors and numerous food or drug interactions contributing to substantial inter- and intrapatient variability in anticoagulation intensity [44]. Genetic mutations in cytochrome P450 (CYP) 2C9 and the vitamin $\mathrm{K}$ epoxide reductase enzyme gene 
VKORC1 are of great importance, but routine use of genetic testing to guide VKA therapy has not been recommended because of a lack of randomized data [45-47]. Noteworthy, an ongoing US trial (the "Genetics informatics trial"), will be the first adequately powered trial to detect a difference in thrombotic and major bleeding events with genotype-guided VKA dosing [48].

\section{Non-vitamin K Oral Anticoagulants}

Numerous difficulties in the long-term management of VKA therapy, including slow onset and offset of anticoagulant effect, the narrow therapeutic window, pronounced inter- and intraindividual variability in the anticoagulant intensity related to the genetic factors and numerous food and drug interactions, thus necessitating regular laboratory monitoring of anticoagulation intensity, as measured by the INR, and the need for frequent dose adjustments, as guided by the INR values, prompted the efforts to develop alternative oral medication. The ideal anticoagulant should target a specific coagulation factor, with a predictable, dose-related anticoagulant effect, and comparable efficacy as VKAs and possibly better safety than VKAs [49]. NOACs [also referred to as DOACs (direct oral anticoagulants)] fulfill most of these criteria, but still have some limitations (Table 1).

\section{Oral Direct Thrombin Inhibitors}

The oral direct thrombin inhibitor dabigatran etexilate was the first approved non-vitamin $\mathrm{K}$ oral anticoagulant [50] (Fig. 1, Table 1).

The pivotal, randomized, phase III clinical trial that established the efficacy and safety of dabigatran in comparison to dose-adjusted warfarin for the prevention of stroke and systemic embolism in patients with non-valvular $\mathrm{AF}$, the "RE-LY" (Randomized Evaluation of Long-Term Anticoagulation Therapy) trial, showed non-inferiority of dabigatran $110 \mathrm{mg}$ twice daily and superiority of dabigatran $150 \mathrm{mg}$ twice daily in comparison to warfarin in the reduction of stroke and systemic embolism, with lower rates of major bleeding in the 110-mg-dose treatment arm and comparable major bleeding rates in the 150-mg-dose treatment arm relative to the warfarin-treated patients [51, 52].

Both dabigatran doses tested in the RE-LY trial (i.e., 150 and $110 \mathrm{mg}$ ) were subsequently approved in Europe, whilst in the USA only the $150 \mathrm{mg}$ dose and the $75 \mathrm{mg}$ dose, which was never tested in a RCT, were approved. Numerous large observational studies investigating the "real-world" safety and effectiveness of dabigatran in routine clinical practice broadly confirmed the RE-LY findings [53-60]. Dabigatran 150 and $110 \mathrm{mg}$ twice daily showed comparable results in the prevention of ischemic stroke and systemic embolism compared to VKAs. Key findings concerning bleeding complications have been a significant reduction in the risk of intracranial hemorrhage and comparable or lower major bleeding rates with dabigatran compared to VKAs, whereas the reports on the risk of gastrointestinal bleeding with dabigatran were conflicting, with overall tendency towards the higher gastrointestinal bleeding risk with dabigatran relative to warfarin $[60,61]$.

Dabigatran is predominantly eliminated renally ( $\sim 80 \%$ of the ingested dose). The prespecified RE-LY subgroup analysis revealed consistent effects of both dabigatran doses relative to warfarin in patients with moderate renal dysfunction [62]. However, major bleeding rates were higher in all three treatment arms in patients with impaired renal function compared to those with preserved renal function. Importantly, patients with severe renal failure [creatinine clearance $(\mathrm{CrCl})<30 \mathrm{ml} / \mathrm{min}$ ] were excluded from the RE-LY study. As per the European label, dabigatran should not be used if $\mathrm{CrCl}$ is below $30 \mathrm{ml} / \mathrm{min}$, whilst the US label allows the use of $75 \mathrm{mg}$ twice daily in patients with a $\mathrm{CrCl}$ of $15-30 \mathrm{ml} / \mathrm{min}[17,19,63]$. Despite the lack of high-quality evidence, dabigatran has been prescribed to hemodialysis patients. However, reported results with higher rates of hemorrhagic deaths in patients on hemodialysis and on dabigatran compared to warfarin were alarming [64].

The RE-LY trial showed an age-related risk of bleeding with benefits of 110 over $150 \mathrm{mg}$ dose 
Table 1 Overview of non-vitamin $\mathrm{K}$ oral anticoagulant drugs $[50,52,62,68,72,74-77,89-91,96-100,105,158]$

\begin{tabular}{|c|c|c|c|c|}
\hline & Dabigatran etexilate & Rivaroxaban & Apixaban & Edoxaban \\
\hline EMA approval & March 2008 & $\begin{array}{l}\text { September } \\
2008\end{array}$ & May 2011 & June 2015 \\
\hline FDA approval & October 2010 & July 2011 & December 2012 & January 2015 \\
\hline $\begin{array}{l}\text { Pivotal phase III } \\
\text { clinical trial }\end{array}$ & RE-LY & ROCKET AF & ARISTOTLE & ENGAGE AF-TIMI 48 \\
\hline Prodrug & Yes & No & No & No \\
\hline Mechanism & Direct thrombin inhibitor & $\begin{array}{l}\text { Direct factor } \\
\mathrm{Xa} \text { inhibitor }\end{array}$ & $\begin{array}{l}\text { Direct factor } \\
\text { Xa inhibitor }\end{array}$ & Direct factor Xa inhibitor \\
\hline $\begin{array}{l}\text { Absolute } \\
\text { bioavailability (\%) }\end{array}$ & 6.5 & $\geq 80$ & 50 & 62 \\
\hline $\begin{array}{l}\text { Time to peak } \\
\text { concentration }(\mathrm{h})\end{array}$ & $0.5-2$ & $2.5-4$ & $3-4$ & $1-2$ \\
\hline Half-life (h) & $12-17$ & $5-13$ & $8-15$ & $6-11$ \\
\hline Metabolism by CYP & No & Yes & Yes & Yes \\
\hline $\begin{array}{l}\text { P-glycoprotein } \\
\text { substrate }\end{array}$ & Yes & Yes & Yes & Yes \\
\hline $\begin{array}{l}\text { Excretion via urine as } \\
\text { unchanged active } \\
\text { drug }(\%)\end{array}$ & 80 & $33-50$ & 25 & 50 \\
\hline \multirow[t]{4}{*}{ Dose monitoring } & $\begin{array}{l}\text { Modification of the thrombin } \\
\text { generation test }\end{array}$ & Anti-FXa assay & Anti-FXa assay & Anti-FXa assay \\
\hline & Diluted thrombin time (dTT) & & & \\
\hline & $\begin{array}{l}\text { Activated partial } \\
\text { thromboplastin time (aPTT) }\end{array}$ & & & \\
\hline & Ecarin clotting time (ECT) & & & \\
\hline \multicolumn{5}{|c|}{ Dosing recommendation (according to prescribing information) } \\
\hline Standard dose & $150 \mathrm{mg}$ bid & $20 \mathrm{mg} \mathrm{qd}$ & $5 \mathrm{mg}$ bid & $60 \mathrm{mg} \mathrm{qd}$ \\
\hline Reduced dose & $110 \mathrm{mg} \mathrm{bid}^{\mathrm{a}}$ & $15 \mathrm{mg} \mathrm{qd}$ & $2.5 \mathrm{mg}$ bid & $30 \mathrm{mg} \mathrm{qd}$ \\
\hline \multirow[t]{3}{*}{ Reduce dose if } & Age $\geq 80$ years & $\begin{array}{l}\mathrm{CrCl} \\
15-49 \mathrm{ml} / \\
\min \end{array}$ & $\begin{array}{l}\text { Two out of } \\
\text { three: }\end{array}$ & $\begin{array}{l}\text { One or more of the } \\
\text { following: }\end{array}$ \\
\hline & Co-medication with verapamil & & Age $\geq 80$ years & $\mathrm{CrCl} 15-50 \mathrm{ml} / \mathrm{min}$ \\
\hline & Consider dose reduction: & & $\begin{array}{l}\text { Body weight } \\
\leq 60 \mathrm{~kg}\end{array}$ & Low body weight $\leq 60 \mathrm{~kg}$ \\
\hline
\end{tabular}


Table 1 continued

\begin{tabular}{|c|c|c|c|c|}
\hline & Dabigatran etexilate & Rivaroxaban & Apixaban & Edoxaban \\
\hline \multicolumn{2}{|r|}{$\mathrm{CrCl} 30-49 \mathrm{ml} / \mathrm{min}$} & & \multirow[t]{4}{*}{$\begin{array}{l}\text { Serum } \\
\text { creatinine } \\
\geq 1.5 \mathrm{mg} / \mathrm{dl}\end{array}$} & \multirow[t]{4}{*}{$\begin{array}{l}\text { Co-medication with strong } \\
\text { P-gp inhibitors (e.g., } \\
\text { dronedarone) }\end{array}$} \\
\hline & Age $75-80$ years & & & \\
\hline & $\begin{array}{l}\text { Gastritis, } \\
\text { gastroesophageal reflux disease }\end{array}$ & & & \\
\hline & Increased risk of bleeding & & & \\
\hline $\begin{array}{l}\text { If } \mathrm{CrCl} 15-29 \mathrm{ml} / \\
\min \end{array}$ & Not recommended & Reduced dose & Reduced dose & Reduced dose \\
\hline $\begin{array}{l}\text { Gastrointestinal } \\
\text { intolerance }\end{array}$ & Dyspepsia and esophagitis & None & None & None \\
\hline $\begin{array}{l}\text { Antidote/reversal } \\
\text { agent }\end{array}$ & Idarucizumab & Andexanet alfa ${ }^{b}$ & Andexanet alfa ${ }^{b}$ & Andexanet alfa ${ }^{b}$ \\
\hline \multicolumn{5}{|c|}{$\begin{array}{l}\text { bid twice a day, } C Y P \text { cytochrome P450, EMA European Medicines Agency, } \\
\text { once a day, } C r C l \text { creatinine clearance } \\
\text { a } 75 \mathrm{mg} \text { bid available in the USA } \\
\text { b Manufacturer currently seeking licensure in North America and Europe }\end{array}$} \\
\hline
\end{tabular}

in patients 75 years or older, as was also demonstrated in a recent meta-analysis $[65,66]$. Dose reduction depending on additional patient-specific risk factors should therefore be considered [34].

In addition, caution should be exercised regarding simultaneous administration of P-glycoprotein inhibitors and inducers, as dabigatran etexilate is a P-glycoprotein substrate [67].

The most common side effect is dyspepsia and it has been recently suggested that it is not only the upper abdominal pain but definite esophagitis, maybe due to the tartaric acid in dabigatran etexilate capsules [68]. The increased risk of myocardial infarction amongst patients on dabigatran is currently under debate [69-71].

\section{Oral Direct Thrombin Inhibitors Antidote}

The weak point of nonexistent reversal agents in NOAC therapy has now been overcome with the new antidote idarucizumab. Idarucizumab, a monoclonal antibody fragment, binds dabigatran with a 350 times higher affinity compared to thrombin and acts rapidly [72]. The full-cohort analysis of the "RE-VERSE AD" (Reversal Effects of Idarucizumab on Active Dabigatran) study showed recently that idarucizumab is effective for dabigatran reversal among patients with uncontrollable or life-threatening bleeding or patients who were about to undergo urgent surgery or invasive procedures [73].

\section{Oral Factor Xa Inhibitors}

\section{Rivaroxaban}

The direct oral factor $\mathrm{Xa}$ inhibitor rivaroxaban inhibits free, clot-bound, and within-prothrombinase-complex factor Xa (Fig. 1) [74] and has an oral bioavailability of nearly $100 \%$ when taken with food. The pivotal, randomized, phase III clinical trial "ROCKET AF" (Rivaroxaban Once Daily Oral Direct Factor Xa Inhibition Compared with Vitamin K Antagonism for Prevention of Stroke and Embolism Trial in AF) 


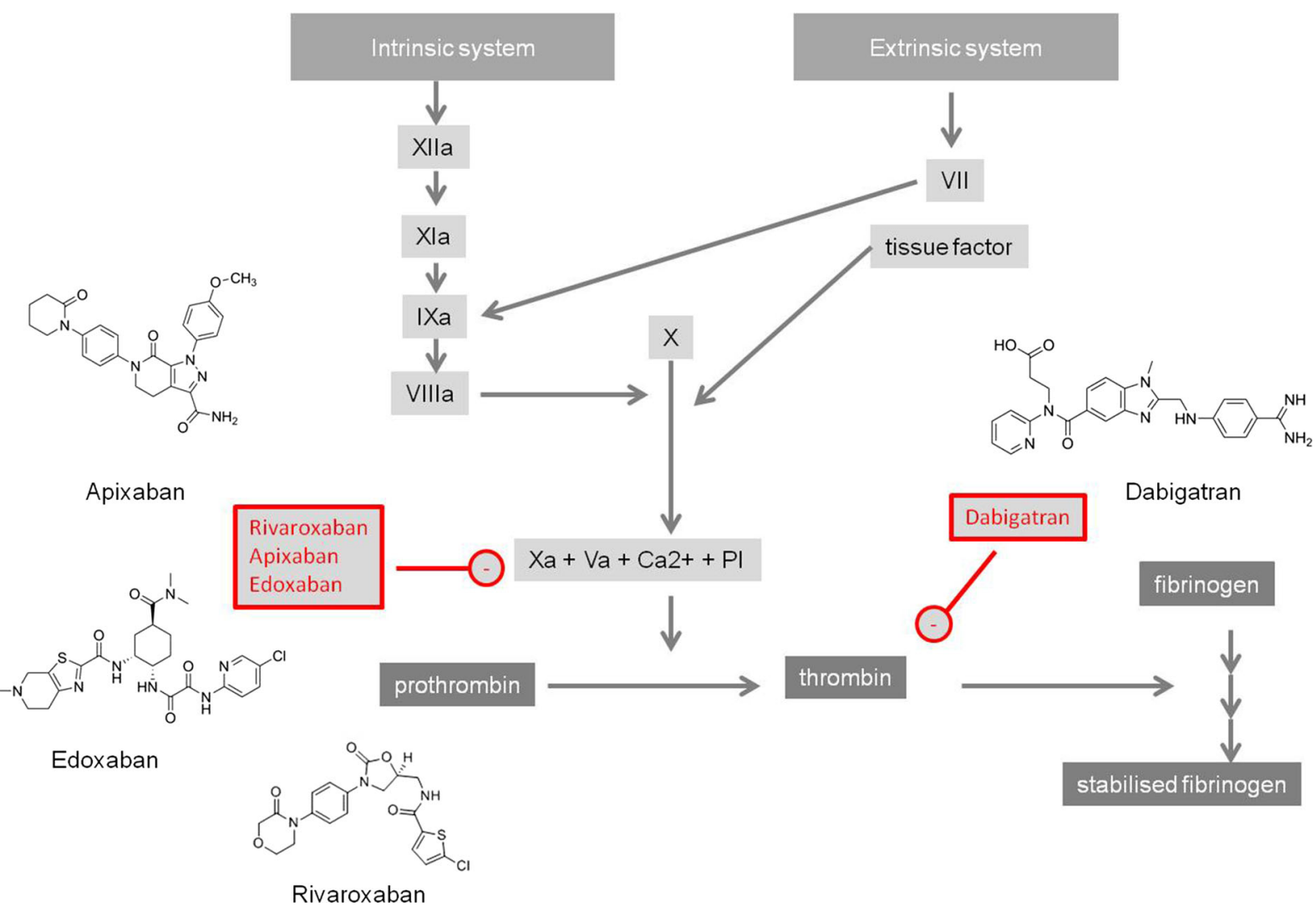

Fig. 1 Schematic coagulation cascade and anticoagulants. Extrinsic and intrinsic coagulation pathways are displayed showing targets of direct factor Xa inhibitors and direct thrombin inhibitor. The chemical structure information for rivaroxaban, apixaban, edoxaban, and dabigatran are available in the PubChem Substance and Compound

showed non-inferiority for prevention of stroke or systemic embolism compared to warfarin in 2011 [75]. One-third of rivaroxaban is eliminated in the urine and $7 \%$ in the feces [76] (Table 1). In the ROCKET AF patients received $20 \mathrm{mg}$ rivaroxaban daily with normal renal function or mild impairment and $15 \mathrm{mg}$ daily with an $\mathrm{CrCl}$ between 30 and $49 \mathrm{ml} / \mathrm{min}$. Rivaroxaban is also approved in Europe for patients with severely reduced kidney function ( $\mathrm{CrCl} 15-29 \mathrm{ml} / \mathrm{min})$ with the reduced dose regime, i.e., $15 \mathrm{mg}$ daily [77].

Notably, there has been a large debate about the ROCKET AF results and in particular with regard to the INR measurements, as the device used to measure INR values in the warfarin arm was recalled by the FDA in December 2014 database through the following identifier numbers: rivaroxaban-PubChem CID 9875401, CAS 366789-02-8; apixaban-PubChem CID 10182969, CAS 503612-47-3; edoxaban-PubChem CID 10280735, CAS 697761-98-1; dabigatran-PubChem CID 216210, CAS 211915-06-9 [159]

because of lower INR values compared to those found by a laboratory method [78]. However, subsequent analyses have shown that this could not have altered the main trial results [79].

The "XANTUS" trial (Xarelto on Prevention of Stroke and Non-central Nervous System Systemic Embolism in Patients with Non-valvular Atrial Fibrillation), a prospective, non-interventional study conducted at 311 centers across Europe, Canada, and Israel reported low stroke rates and even lower rates of major bleedings than in ROCKET AF with the selected dose regime at the discretion of the treating physician [80]. Other "real-world" data reports and large registries also confirmed safety of rivaroxaban treatment in heterogeneous patient populations [81, 82]. Although rivaroxaban has 
been reported to have an inferior profile concerning major bleeding in "real-world" pairwise comparisons to dabigatran and apixaban but comparable to warfarin [83-86], such comparisons have numerous limitations. Indeed, the risk for intracranial hemorrhage has been proven to be lower in patients on rivaroxaban compared to warfarin as shown in the "REVISIT-US" (Real-World Evidence on Stroke Prevention in Patients with Atrial Fibrillation in the United States) study. The REVISIT-US is a retrospective administrative claims database study, wherein 11,411 rivaroxaban users were propensity score matched 1:1 to warfarin users and rivaroxaban use was associated with a $47 \%$ reduction in hazard ratio concerning intracranial hemorrhage compared to warfarin [82].

Rivaroxaban has been associated with better compliance in real-world data due to once-a-day dosing compared to twice-daily dosing of apixaban and dabigatran, although this finding could not be consistently validated in all recent studies [87, 88]. On the other hand, as the anticoagulant effect declines rapidly after even one missed dose, strict adherence to the prescribed dosing regime is crucial.

\section{Apixaban}

Apixaban is the third approved NOAC, a potent direct factor Xa inhibitor (Fig. 1) which is predominantly eliminated hepatically [89] (Table 1).

Apixaban has been evaluated in two key clinical trials. The AVERROES (Apixaban Versus Acetylsalicylic Acid to Prevent Stroke in AF Patients Who Have Failed or Are Unsuitable for Vitamin K Antagonist Treatment) trial was a randomized, double-blinded study that compared apixaban to aspirin in patients unsuitable for VKA therapy [90]. Patients received a dose of $5 \mathrm{mg}$ apixaban twice daily or a reduced dose of $2.5 \mathrm{mg}$ twice daily when meeting two out of three of the following criteria: age $\geq 80$ years, body weight $\leq 60 \mathrm{~kg}$, and serum creatinine $\geq 133 \mu \mathrm{mol} / \mathrm{l}$. The patients randomized to the aspirin therapy arm received one to four $81 \mathrm{mg}$ aspirin doses per day at the discretion of the treating physician. The trial was terminated prematurely because of the marked superiority of apixaban for preventing strokes and systemic embolism, with comparable bleeding risks between the two arms [90].

The ARISTOTLE (Apixaban for Reduction in Stroke and Other Thromboembolic Events in AF) trial was a randomized trial comparing apixaban with warfarin to prevent stroke and systemic embolism among 18,201 patients with AF [91]. The recommended study doses of apixaban were the same as described in the AVERROES trial. Besides non-inferiority it also demonstrated superiority over warfarin in terms of primary outcomes, i.e., stroke or systemic embolism, major bleeding, and all-cause mortality [91].

Since its approval, apixaban has been evaluated in large registries [84, 92, 93] and showed a particularly favorable risk profile concerning major bleeding risk, that has been found consistently in recent studies [84, 85]. Recommended dose has been reduced in ARISTOTLE and AVERROES as stated above in patients meeting two of the following criteria: age $\geq 80$ years, serum creatinine $\geq 1.5 \mathrm{mg} / \mathrm{dl} \quad(133 \mu \mathrm{mol} / \mathrm{l}), \quad$ or weight $\leq 60 \mathrm{~kg}$, which represents the current recommendation of the European label. In a recently published renal function-centered analysis of the ARISTOTLE trial, efficacy and safety were reported to be similar in patients with normal, poor, and worsening renal function compared to warfarin [94].

As apixaban has the highest percentage of hepatobiliary metabolism of all NOACs, caution should be taken in the setting of advanced hepatic failure as studies concerning risk profile of this specific patient population are lacking [95]. Apixaban is metabolized via the CYP450 system leading to certain drug interactions and, just like the other factor Xa inhibitors, apixaban is a substrate of P-glycoprotein [96].

\section{Edoxaban}

Edoxaban, a direct factor Xa inhibitor, is the fourth NOAC approved for prevention of stroke and other thromboembolic events in patients with atrial fibrillation [97].

Like rivaroxaban, edoxaban is applied once daily, on the basis of a randomized clinical phase II study that found significantly higher bleeding rates compared to warfarin for the twice daily dose regime compared to the once 
daily application [98]. Although edoxaban is promoted as trouble-free concerning CYP450 system interactions because it is metabolized via hydrolysis, it shows interaction with P-glycoprotein (P-gp) inhibitors, but is the only factor $\mathrm{Xa}$ inhibitor not contraindicated in co-medication with strong inhibitors of both CYP3A4 and P-glycoprotein, such as dronedarone (Table 1) [99]. Excretion is $50 \%$ renal leading to a recommended dose reduction to $30 \mathrm{mg}$ daily in patients with renal impairment (Table 1) [97]. The pivotal, randomized, phase III clinical trial to evaluate edoxaban, ENGAGE AF-TIMI 48 (The Effective Anticoagulation with Factor Xa Next Generation in AF-Thrombolysis in Myocardial Infarction 48), compared two different doses of edoxaban (30 and $60 \mathrm{mg}$ ) to warfarin [100]. In the ENGAGE AF-TIMI 48 trial the edoxaban dose was halved if the estimated $\mathrm{CrCl}$ was $30-50 \mathrm{ml} / \mathrm{min}$, patient's body weight was $60 \mathrm{~kg}$ or less, or if there was concomitant use of verapamil or quinidine as they represent potent P-glycoprotein inhibitors. The trial showed non-inferiority of edoxaban to warfarin in the prevention of stroke or systemic embolism and significantly lower rates of bleeding and death from cardiovascular causes. Of note, the TTR in the warfarin arm was $68.4 \%$ and thus higher than in all the other pivotal NOAC trials $[52,75,91]$. Worthy of discussion, a post hoc analysis of the ENGAGE AF-TIMI 48 trial reported higher efficacy in patients with mild kidney dysfunction compared to patient with normal kidney function with a $\mathrm{CrCl}>95 \mathrm{ml} /$ min. In patients with normal $\mathrm{CrCl}$ the risks of stroke and systemic embolism were in favor of warfarin therapy [101] perhaps due to lower drug exposure in patients with normal kidney function. This is currently under debate and calls for further investigation concerning optimal edoxaban dosing in patients without renal impairment [102, 103]. Gathering of real-world data on safety and effectiveness of edoxaban is currently under way.

\section{Factor Xa Inhibitor Antidote}

Andexanet alfa is a recombinant factor $\mathrm{Xa}$ molecule with higher affinity for natural factor
$\mathrm{Xa}$ inhibitor than endogenous factor $\mathrm{Xa}$, thus reversing factor Xa inhibition. In the two randomized controlled trials ANNEXA-A (Andexanet Alfa a Novel Antidote to the Anticoagulant Effects of FXa Inhibitors-Apixaban) and ANNEXA-R (Andexanet Alfa a Novel Antidote to the Anticoagulant Effects of FXa Inhibitors-Rivaroxaban), the new antidote was tested in older healthy volunteers, showing reversing effects within 2-5 min after bolus administration, sustaining during continuous infusion, and fading effects approximately $1-3 \mathrm{~h}$ after cessation of administration [104]. More recently, the reversal agent was tested in 67 patients with acute major bleeding [105]. Further clinical trials on efficacy and safety are pending.

\section{From VKA to NOAC: Implicated Challenges}

In clinical practice, patients switch more and more often from VKA to NOAC therapy. Whether the switching process involves a higher risk for bleeding complication has been the subject of current studies. A recently published French matched-cohort study, based on administrative national health-insurance data in combination with a hospital discharge database, investigated a total of 6705 switchers, defined as patients previously on VKA therapy who switched to NOACs, compared to 10,705 patients remaining on VKAs. With the limitation of a relatively short follow-up period, no difference between groups for bleeding events was observed [106]. Another hot topic in NOAC therapy is co-medication with antiplatelet drugs (triple therapy) due to coronary artery disease and consecutive interventions and has been discussed in detail elsewhere [107]. In addition, special situations, e.g., new-onset atrial fibrillation post cardiac surgery and anticoagulation during cardioversion or catheter ablation, are currently extensively studied [108-110]. Although the problem of slow therapeutic onset and offset of anticoagulant effect in warfarin treatment could be overcome with NOACs, there is some evidence that the skipping of one dose has a more detrimental effect, especially in NOACs with 
once-daily dosing [111]. The compliance of NOAC intake and measures to maximize it are therefore currently studied extensively [112]. Another important topic is the medical costs, which are prima facie higher in NOAC than in VKA therapy and thus may limit access to NOACs [113]. However, recently published cost-effectiveness analyses showed that NOACs provide a decent cost-effectiveness owing to clinical benefits and this has been shown in several countries $[113,114]$. It will be interesting how world-wide anticoagulation standards will change in the next few years. The Global Registry on Long-Term Oral Antithrombotic Treatment in Patients with Atrial Fibrillation (GLORIA-AF) provides interesting insights into the world-wide prescription changes during the conversion period with introduction of NOACs $[115,116]$.

\section{Future NOACs in the Pipeline}

At the moment, there are additional NOACs in clinical testing [49]. Betrixaban is a specific and reversible factor $\mathrm{Xa}$ inhibitor that has been developed to overcome dose adjustment in patients with renal impairment. Betrixaban is excreted in the gut (82-89\%), but uses the P-glycoprotein efflux pump like the other factor $\mathrm{X}$ inhibitors [117]. RCTs for stroke prevention in atrial fibrillation are lacking to date but the phase III clinical trial "APEX" (Acute Medically Ill Venous Thromboembolism Prevention with Extended Duration Betrixaban) [118, 119] retrospective substudy showed a reduced all-cause stroke and ischemic stroke through 77 days follow-up [120]. TTP889, a selective factor IXa antagonist, and GCC-4401C, a direct factor Xa inhibitor, are two other anticoagulants currently in clinical testing [121, 122].

\section{LEFT ATRIAL APPENDAGE LIGATION AND CLOSURE}

Different approaches have been evaluated to get rid of "our most lethal attachment" [123]. Currently available and broad applied techniques and devices include surgical ligation and excisions, stapling tools as well as epicardial clips [124, 125].

Surgical left atrial appendage closure has been performed for decades and it also a convenient supplemental procedure in hearts that are already exposed during cardiac surgery. However, profound evidence through randomized controlled prospective trials supporting this approach for stroke prevention is lacking [126]. In 2005 the Left Atrial Appendage Occlusion Study (LAAOS), the first randomized, non-blinded study of surgical LAA occlusion was conducted, comparing the two arms LAA occlusion or control with a 2:1 randomization favoring LAA occlusion. Not addressing stroke prevention itself but safety and feasibility, the study reported LAA occlusion in $66 \%$ of the patients randomized to the LAA occlusion arm. Two mechanisms of failure of sufficient LAA closure using either stapling devices or surgical sutures have been described: (1) persistent flow across suture lines and (2) stapling too distally with a residual LAA stump greater than $1 \mathrm{~cm}$ [127]. A more recent study from Lee et al. even identified insufficient LAA closure with surgical techniques via intraoperative transesophageal echocardiography (TEE) in up to $63 \%$ [125]. Of note, insufficient closure seems to be more harmful and thrombogenic than no closure at all [128, 129].

Introduced in 2014, the LAAOS III trial aims to determine stroke risk by comparing patients undergoing elective cardiac surgery with concomitant surgical LAA closure and without LAA closure, respectively [130]. Although final results after the 4-year follow-up period are eagerly awaited, it has to be pointed out that anticoagulation will be continued in both groups. Current guidelines recommend to continue anticoagulation in at-risk patients after surgical occlusion or exclusion of the LAA as well. However, even if different stroke risk components are addressed (anatomic region of thrombus formation versus decreased affinity of thrombus formation) it appears controversial to continue OAC after LAA occlusion or exclusion per se [16].

Another method for LAA occlusion during cardiac surgery is a clip device ("AtriClip") that is placed epicardially at the base of the left atrial 
appendage. Study reports from the "EXCLUDE" (Exclusion Device in Patients Undergoing Concomitant Cardiac Surgery) trial suggested a fast, atraumatic, and highly successful left atrial appendage occlusion [131], and possible application of the device in off-pump surgery has been shown very recently [132]. Another recently developed tool favors access via mini-thoracotomy and occluding LAA via a clamp consisting of two tubes connected by an elastic bow [133].

\section{INTERVENTIONAL PERCUTANEOUS ENDOCARDIAL AND EPICARDIAL LAA CLOSURE}

In 2002 early experiences with a new device for interventional, percutaneous LAA occlusion were reported. The percutaneous left atrial appendage transcatheter occlusion (PLAATO) device enabled non-invasive occlusion of the left atrial appendage via an implant and delivery catheter [134]. The device was built as a self-expanding nitinol cage covered with an occlusive expanded polytetrafluoroethylene membrane to occlude blood flow into the remaining orifice equipped with three anchors. After the first promising results and implantations the tool was withdrawn from the market in 2006.

The next upcoming device has been the WATCHMAN, which received the CE mark in 2005. The device has a self-expanding nitinol frame covered with a permeable polyethylene terephthalate membrane and ten active fixation anchors. In the multicenter, randomized WATCHMAN Left Atrial Appendage System for Embolic Protection in Patients with AF (PROTECT AF) trial, the device was implanted successfully in $91 \%$ of all cases [135]. It showed non-inferiority in comparison to continued warfarin therapy in the primary composite endpoint stroke, systemic embolism, and cardiovascular death event rates. The rate of the primary adverse procedure-related events, with the most frequent one pericardial effusion, led to the demand of a further trial for FDA approval. Hence, the answer was the "PREVAIL" (Prospective Randomized Evaluation of the
Watchman LAA Closure Device in Patients with AF Versus Long Term Warfarin Therapy) trial that showed significant improvement of procedural safety but failed to meet the non-inferiority criteria [136]. Then again, the extended analysis of the PROTECT AF trial, after 3.8 years of follow-up, concluded both non-inferiority and superiority of the WATCHMAN device compared to warfarin for the combined outcome of stroke, systemic embolism, and cardiovascular death [137]. However, it is important to mention that the patient-level meta-analysis comparing left atrial appendage closure versus systemic therapy (warfarin) published in 2015 also failed to prove non-inferiority in the device group concerning the most interesting isolated endpoint of ischemic stroke but showed a significant reduction of hemorrhagic stroke leading to no significant difference in the rate of all stroke or systemic embolism [138]. In summary, conclusive data concerning left atrial occlusion devices is lacking to date.

The third LAA closure device, the Amplatzer Cardiac Plug (ACP), has a self-expanding nitinol mesh forming a lobe and disk, connected by a central neck. The lobe is implanted $10 \mathrm{~mm}$ inside of the LAA orifice to anchor the device, supported by distally located stabilizing wires arranged crown-like. A procedural success rate of $97.3 \%$ was reported in a multicenter study including a total of 1053 patients from 22 centers [139]. It has been highlighted, however, that the number of periprocedural complications was "moderate" with cardiac tamponade as the leading adverse event. The next generation of the ACP, the Amulet or ACP2, has to be implanted $12 \mathrm{~mm}$ inside the LAA cavity, features stiffer stabilizing wires, and is available in larger disc diameters than its predecessor [140]. Besides the same basic structure, implantation of the Amulet device has been accompanied by a lower rate of non-relevant pericardial effusions, compared to the ACP in an early-experience dual-center cohort study [141].

As it is the case in every intervention, the procedural complication rate is dependent on the interventionist's expertise. Apparently, greatly feared adverse events of left atrial appendage occlusion device implantation are pericardial effusion and device embolization 
which have an occurrence rate of up to $2 \%$ [142]. Pre-interventional imaging aims to maximize procedural safety and success, improving assessment of individual relationships to anatomical adjacent structures [143, 144]. However, a sufficient infrastructure with post-device monitoring interval is mandatory. The European Heart Rhythm Association survey provided insights into clinical practice in 2012 and found out that $73 \%$ of the responding centers performed at most 10 procedures per year. The intervention itself is most often performed by the interventional cardiologist or the electrophysiologist as the primary operator with the patient either under sedation or under general anesthesia. Interestingly, the top three limiting factors in clinical practice have been the cost-intensive acquisition of LAA occlusion devices, the limited efficacy data, and the relevant risk of complications [145].

Current European guidelines recommend left atrial appendage occlusion with class IIb level of evidence $\mathrm{B}$ in patients with $\mathrm{AF}$ and contraindications for long-term $\mathrm{OAC}$ as well as in patients with AF undergoing cardiac surgery or thoracoscopic AF surgery [16].

Pursuant to the goal to reduce bleeding complications, a current matter of debate is the antithrombotic management following left atrial appendage occlusion device implantation [146]. On the one hand, patients selected for device implantation present themselves with a high risk of stroke and high risk of bleeding complications. On the other hand, after successful device implantation, there is a risk for clot formation on the artificial device surface until complete endothelialization has occurred. In the RCTs PROTECT AF and PREVAIL evaluating WATCHMAN performance, patients received postprocedural VKA therapy in combination with aspirin for 45 days followed by 6 months of dual platelet inhibition with clopidogrel and aspirin if closure was successful $[135,136]$. As a result of the high bleeding risk in most patients with indication for left atrial appendage occlusion, this regime appears difficult. Another approach is to treat patients after device implantation for 6 months with dual antiplatelet therapy and with lifelong aspirin thereafter [147]. A randomized controlled trial in OAC-contraindicated patients determining which medical regime is best following left atrial appendage occlusion is lacking, and the antiplatelet and anticoagulation regime after left atrial appendage occlusion is currently diverse in clinical practice.

The LARIAT procedure, a percutaneous catheter-based LAA ligation with a suture delivery component, uses a combined endoand epicardial approach for LAA closure. Following initial reports of bleeding and perforation due to the epicardial access, it has been developed further. The basic principle of pericardial and trans-septal access followed by the placement of the endocardial magnet-tipped guidewire in the LAA and connection of the epicardial and endocardial magnet-tipped guidewires for stabilization, positioning of a snare, and release of a pretied suture for LAA ligation, however, has not changed [148]. In 2014 safety and efficacy outcomes of 154 patients enrolled for the LARIAT procedure were reported with quite a few major complications: emergency surgery was required in three patients $(2 \%)$ because of right ventricular perforation, and LAA perforation and major bleeding in a total of 14 patients [149]. Up to now, the LARIAT procedure has not managed to establish itself firmly.

Overall, there are three main open issues in the field of left atrial appendage occlusion: First, the available data cannot be considered sufficient. It is remarkable that our current practice is mainly based on data from 1114 patients randomized in the PROTECT AF and PREVAIL studies [136, 138]. This is a small number of patients from which to draw conclusions for a new treatment strategy for stroke prevention in AF. Second, there is no randomized comparison of interventional LAA occlusion against NOACs. This is important considering the significant reduction of hemorrhagic stroke under NOACs compared with warfarin [150] and the reduced overall risk of major bleeding under NOACs [91]. Third, there is no sufficient data for the patient population for which this technique is currently recommended, namely patients that have a contraindication for OAC. Although non-randomized data suggest that in these patients, at least the short-term outcome is 


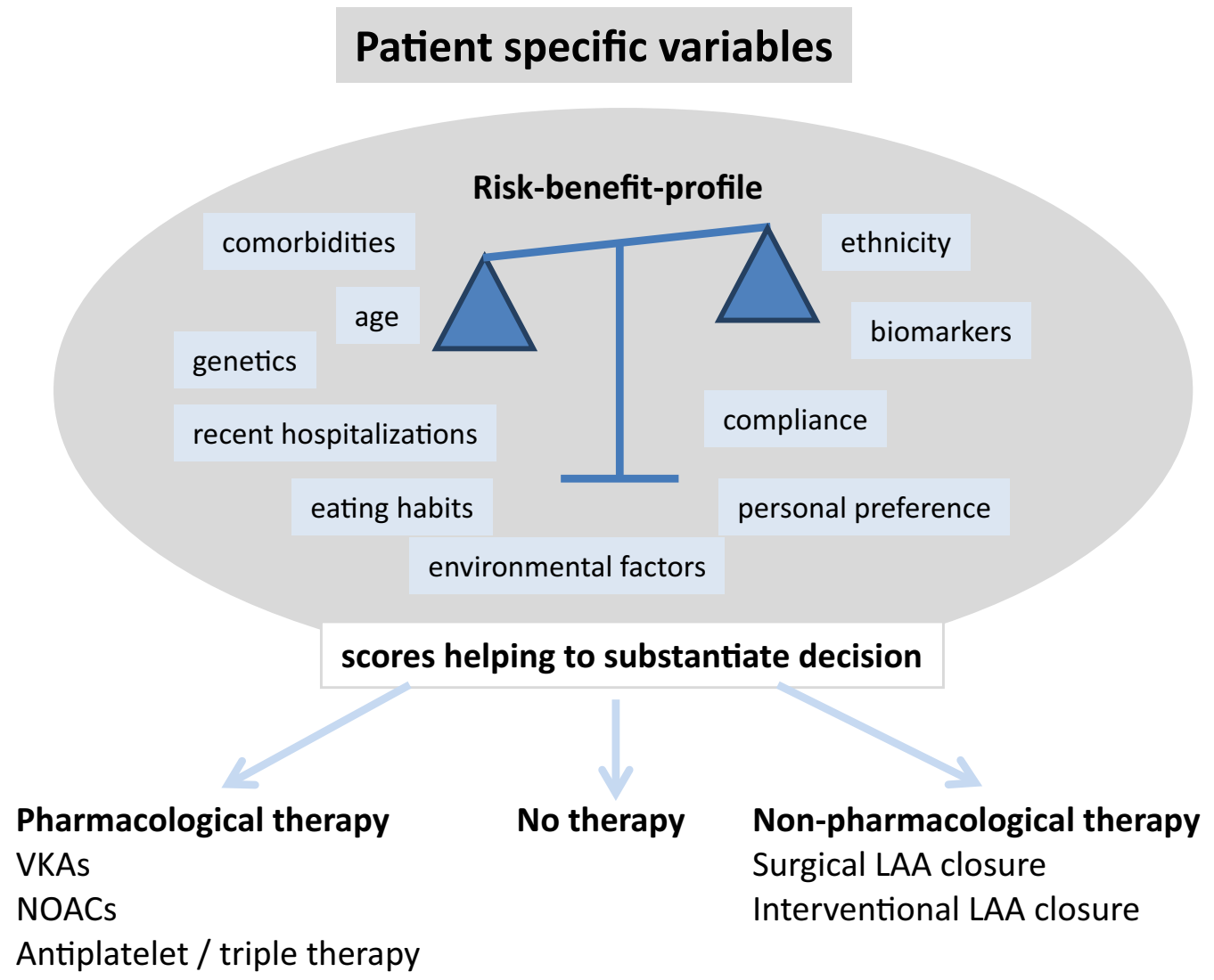

Fig. 2 Patient-specific factors influencing decision-making about oral anticoagulation [10, 25-29, 160]

similar to the group of patients without contraindication against the use of oral anticoagulants [151], the long-term benefit of LAA occlusion in this patient population needs to be confirmed [152].

\section{FUTURE DIRECTIONS}

Albeit often ignored and quoted as having "minimal useful function" [123], the LAA does fulfill a variety of physiologic tasks. It is not just that it operates as a blood reservoir, contracts and thus supports hemodynamics, but it also has a substantial endocrine activity with an atrial natriuretic peptide production of approximately $30 \%$ of the whole heart [153]. Furthermore, it serves as a reservoir for cardiac progenitor cells [154]. Little is known about post-device implantation effects on the aforementioned functions [155, 156]. Besides new direct OACs and improved LAA device technology there is currently no other idea to eliminate stroke risk. New directions would include possibilities for local release of blood-thinning agents to decrease whole body adverse effects of anticoagulation, LAA occlusion devices coated with endogenous cell layers to diminish formation of thrombus at the device surface, and 3D printed LAA models to facilitate guiding and device sizing [157].

\section{CONCLUSIONS}

$\mathrm{AF}$ and risk for stroke are closely interwoven. Thus, a variety of pharmacological and non-pharmacological treatments have been evaluated to reduce thromboembolic risks (Fig. 2). Pharmacological treatment is appropriate and comfortable for a large proportion of patients. Recently, new OACs have been developed with several advantages over classic VKAs. Despite the initial enthusiasm, all of the new 
drugs do have distinct limitations and caution has to be exercised when severe comorbidities are present. Furthermore, the potential for drug interaction is not to be underestimated. Worthy of note is the development of antidotes and reversal agents, which had been a major demand in the last few years.

For patients with a high bleeding risk and thus not suitable for oral anticoagulation, a palette of surgical and non-surgical methods for LAA occlusion are available. Of note, LAA occlusion always entails the possibility of severe complications due to the necessary access or complex device positioning. Currently, this therapy is reserved in clinical practice for patients who have a clear indication for anticoagulation but also a contraindication for such a treatment.

\section{ACKNOWLEDGEMENTS}

No funding or sponsorship was received for publication of this article. All named authors meet the International Committee of Medical Journal Editors (ICMJE) criteria for authorship for this manuscript, take responsibility for the integrity of the work as a whole, and have given final approval for the version to be published.

Disclosures. L. Ueberham reports research grants from Boston Scientific, St. Jude Medical, and Biotronik to the institution (no personal fees). N. Dagres reports research grants from Boston Scientific, St. Jude Medical, and Biotronik to the institution (no personal fees). A. Bollman reports research grants from Boston Scientific, St. Jude Medical, and Biotronik to the institution (no personal fees). G. Hindricks reports research grants from Boston Scientific, St. Jude Medical, and Biotronik to the institution (no personal fees). T. S. Potpara received speaker fees from Bayer and Pfizer.

Compliance with Ethics Guidelines. This article is based on previously conducted studies and does not involve any new studies of human or animal subjects performed by any of the authors.
Open Access. This article is distributed under the terms of the Creative Commons Attribution-NonCommercial 4.0 International License (http://creativecommons.org/licenses/ by-nc/4.0/), which permits any noncommercial use, distribution, and reproduction in any medium, provided you give appropriate credit to the original author(s) and the source, provide a link to the Creative Commons license, and indicate if changes were made.

\section{REFERENCES}

1. Bennell MC, Qiu F, Micieli A, et al. Identifying predictors of cumulative healthcare costs in incident atrial fibrillation: a population-based study. J Am Heart Assoc. 2015;4:e001684.

2. DeVore AD, Hellkamp AS, Becker RC, et al. Hospitalizations in patients with atrial fibrillation: an analysis from ROCKET AF. Europace. 2016;18:1135-42.

3. Biviano AB, Nazif T, Dizon J, et al. Atrial fibrillation is associated with increased mortality in patients undergoing transcatheter aortic valve replacement: insights from the placement of aortic transcatheter valve (PARTNER) trial. Circ Cardiovasc Interv. 2016;9:e002766.

4. Watson T, Shantsila E, Lip GYH. Mechanisms of thrombogenesis in atrial fibrillation: Virchow's triad revisited. Lancet. 2009;373:155-66.

5. Nielsen PB, Larsen TB, Skjoth F, et al. Stroke and thromboembolic event rates in atrial fibrillation according to different guideline treatment thresholds: a nationwide cohort study. Sci Rep. 2016;6:27410.

6. Henninger N, Goddeau RP Jr, Karmarkar A, et al. Atrial fibrillation is associated with a worse 90-day outcome than other cardioembolic stroke subtypes. Stroke. 2016;47:1486-92.

7. Blackshear JL, Odell JA. Appendage obliteration to reduce stroke in cardiac surgical patients with atrial fibrillation. Ann Thorac Surg. 1996;61:755-9.

8. Li CY, Gao BL, Liu XW, et al. Quantitative evaluation of the substantially variable morphology and function of the left atrial appendage and its relation with adjacent structures. PLoS One. 2015;10:e0126818. 
9. Kaminski R, Kosinski A, Brala M, et al. Variability of the left atrial appendage in human hearts. PLoS One. 2015;10:e0141901.

10. Di Biase L, Santangeli P, Anselmino M, et al. Does the left atrial appendage morphology correlate with the risk of stroke in patients with atrial fibrillation? Results from a multicenter study. J Am Coll Cardiol. 2012;60:531-8.

11. Korhonen M, Muuronen A, Arponen O, et al. Left atrial appendage morphology in patients with suspected cardiogenic stroke without known atrial fibrillation. PLoS One. 2015;10:e0118822.

12. Anselmino M, Scaglione M, Di Biase L, et al. Left atrial appendage morphology and silent cerebral ischemia in patients with atrial fibrillation. Heart Rhythm. 2014;11:2-7.

13. Daoud EG, Glotzer TV, Wyse DG, et al. Temporal relationship of atrial tachyarrhythmias, cerebrovascular events, and systemic emboli based on stored device data: a subgroup analysis of TRENDS. Heart Rhythm. 2011;8:1416-23.

14. Brambatti M, Connolly SJ, Gold MR, et al. Temporal relationship between subclinical atrial fibrillation and embolic events. Circulation. 2014;129:2094-9.

15. Kamel H, Okin PM, Elkind MS, et al. Atrial fibrillation and mechanisms of stroke: time for a new model. Stroke. 2016;47:895-900.

16. Kirchhof P, Benussi S, Kotecha D, et al. 2016 ESC guidelines for the management of atrial fibrillation developed in collaboration with EACTS: The Task Force for the management of atrial fibrillation of the European Society of Cardiology (ESC) developed with the special contribution of the European Heart Rhythm Association (EHRA) of the ESC endorsed by the European Stroke Organisation (ESO). Eur Heart J. 2016;37:2893-962.

17. January CT, Wann LS, Alpert JS, et al. 2014 AHA/ ACC/HRS guideline for the management of patients with atrial fibrillation: a report of the American College of Cardiology/American Heart Association Task Force on practice guidelines and the Heart Rhythm Society. J Am Coll Cardiol. 2014;64:e1-76.

18. Macle L, Cairns J, Leblanc K, et al. 2016 focused update of the Canadian Cardiovascular Society guidelines for the management of atrial fibrillation. Can J Cardiol. 2016;32:1170-85.

19. You JJ, Singer DE, Howard PA, et al. Antithrombotic therapy for atrial fibrillation: antithrombotic therapy and prevention of thrombosis, 9th ed: American College of Chest Physicians evidence-based clinical practice guidelines. Chest. 2012;141: e531S-75S.
20. Potpara TS, Dagres N, Mujovic N, et al. Decision-making in clinical practice: oral anticoagulant therapy in patients with non-valvular atrial fibrillation and a single additional stroke risk factor. Adv Ther. 2017;34(2):357-377.

21. Chao TF, Liu CJ, Wang KL, et al. Should atrial fibrillation patients with 1 additional risk factor of the CHA2DS2-VASc score (beyond sex) receive oral anticoagulation? J Am Coll Cardiol. 2015;65:635-42.

22. Lip GY, Skjoth F, Rasmussen LH, et al. Oral anticoagulation, aspirin, or no therapy in patients with nonvalvular AF with 0 or 1 stroke risk factor based on the CHA2DS2-VASc score. J Am Coll Cardiol. 2015;65:1385-94.

23. Fauchier L, Lecoq C, Clementy N, et al. Oral anticoagulation and the risk of stroke or death in patients with atrial fibrillation and one additional stroke risk factor: the Loire Valley Atrial Fibrillation Project. Chest. 2016;149:960-8.

24. Hamatani Y, Ogawa H, Takabayashi K, et al. Left atrial enlargement is an independent predictor of stroke and systemic embolism in patients with non-valvular atrial fibrillation. Sci Rep. 2016;6:31042.

25. Kabra R, Girotra S, Vaughan Sarrazin M. Refining stroke prediction in atrial fibrillation patients by addition of African-American ethnicity to CHA2DS2-VASc score. J Am Coll Cardiol. 2016;68:461-70.

26. Barra S, Almeida I, Caetano F, et al. Stroke prediction with an adjusted R-CHA2DS2VASc score in a cohort of patients with a myocardial infarction. Thromb Res. 2013;132:293-9.

27. Cohen A, Ederhy S, Meuleman C, et al. D-dimers in atrial fibrillation: a further step in risk stratification of thrombo-embolism? Eur Heart J. 2007;28:2179-80.

28. Hijazi Z, Oldgren J, Andersson U, et al. Cardiac biomarkers are associated with an increased risk of stroke and death in patients with atrial fibrillation: a randomized evaluation of long-term anticoagulation therapy (RE-LY) substudy. Circulation. 2012;125:1605-16.

29. Shibazaki K, Kimura K, Aoki J, et al. Brain natriuretic peptide level on admission predicts recurrent stroke after discharge in stroke survivors with atrial fibrillation. Clin Neurol Neurosurg. 2014;127:25-9.

30. Rillig A, Tilz RR, Lin T, et al. Unexpectedly high incidence of stroke and left atrial appendage thrombus formation after electrical isolation of the left atrial appendage for the treatment of atrial 
tachyarrhythmias. Circ Arrhythm Electrophysiol. 2016;9:e003461.

31. Zhang J, Tang C, Zhang Y, et al. Electrophysiologic and clinical consequences of left atrial anterior wall linear ablation in patients with persistent atrial fibrillation. J Cardiovasc Electrophysiol. 2015. doi:10.1111/jce.12713.

32. Di Biase L, Natale A. Left atrial appendage after electrical isolation: to occlude or not to occlude, that is the question. Circ Arrhythm Electrophysiol. 2016;9. doi:10.1161/CIRCEP.116.004372.

33. Pisters R, Lane DA, Nieuwlaat R, et al. A novel user-friendly score (HAS-BLED) to assess 1-year risk of major bleeding in patients with atrial fibrillation: the Euro Heart Survey. Chest. 2010;138:1093-100.

34. Potpara TS, Lip GY. Oral anticoagulant therapy in atrial fibrillation patients at high stroke and bleeding risk. Prog Cardiovasc Dis. 2015;58:177-94.

35. Stahmann MA, Huebner CF, Link KP. Studies on the hemorrhagic sweet clover disease. J Biol Chem. 1940;136:513-27.

36. Hart RG. Meta-analysis: antithrombotic therapy to prevent stroke in patients who have nonvalvular atrial fibrillation. Ann Intern Med. 2007;146:857.

37. Ageno W, Gallus AS, Wittkowsky A, et al. Oral anticoagulant therapy: antithrombotic therapy and prevention of thrombosis, 9th ed: American College of Chest Physicians evidence-based clinical practice guidelines. Chest. 2012;141:e44S-88S.

38. Dentali F, Crowther M, Galli M, et al. Effect of vitamin $\mathrm{K}$ intake on the stability of treatment with vitamin $\mathrm{K}$ antagonists: a systematic review of the literature. Semin Thromb Hemost. 2016;42(6):671-81.

39. Violi F, Lip GY, Pignatelli P, et al. Interaction between dietary vitamin $\mathrm{K}$ intake and anticoagulation by vitamin $\mathrm{K}$ antagonists: is it really true?: a systematic review. Medicine (Baltimore). 2016;95:e2895.

40. Schein JR, White CM, Nelson WW, et al. Vitamin K antagonist use: evidence of the difficulty of achieving and maintaining target INR range and subsequent consequences. Thromb J. 2016;14:14.

41. Connolly SJ, Pogue J, Eikelboom J, et al. Benefit of oral anticoagulant over antiplatelet therapy in atrial fibrillation depends on the quality of international normalized ratio control achieved by centers and countries as measured by time in therapeutic range. Circulation. 2008;118:2029-37.

42. Wieloch M, Sjalander A, Frykman V, et al. Anticoagulation control in Sweden: reports of time in therapeutic range, major bleeding, and thrombo-embolic complications from the national quality registry AuriculA. Eur Heart J. 2011;32:2282-9.

43. Apostolakis S, Sullivan RM, Olshansky B, et al. Factors affecting quality of anticoagulation control among patients with atrial fibrillation on warfarin: the SAMe-TT(2)R(2) score. Chest. 2013;144: 1555-63.

44. Ufer M. Comparative pharmacokinetics of vitamin $\mathrm{K}$ antagonists: warfarin, phenprocoumon and acenocoumarol. Clin Pharmacokinet. 2005;44: 1227-46.

45. Pirmohamed M, Kamali F, Daly AK, et al. Oral anticoagulation: a critique of recent advances and controversies. Trends Pharmacol Sci. 2015;36:153-63.

46. Furie B. Do pharmacogenetics have a role in the dosing of vitamin $\mathrm{K}$ antagonists? N Engl J Med. 2013;369:2345-6.

47. Johnson JA, Cavallari LH. Warfarin pharmacogenetics. Trends Cardiovasc Med. 2015;25:33-41.

48. Do EJ, Lenzini P, Eby CS, et al. Genetics informatics trial (GIFT) of warfarin to prevent deep vein thrombosis (DVT): rationale and study design. Pharmacogenom J. 2012;12:417-24.

49. Shantsila E, Lip GYH. Non-vitamin K antagonist oral anticoagulants. A concise guide. Berlin: Springer; 2016.

50. Di Nisio M, Middeldorp S, Buller HR. Direct thrombin inhibitors. N Engl J Med. 2005;353:1028-40.

51. Connolly SJ, Wallentin L, Ezekowitz MD, et al. The long-term multicenter observational study of dabigatran treatment in patients with atrial fibrillation (RELY-ABLE) study. Circulation. 2013;128:237-43.

52. Connolly SJ, Ezekowitz MD, Yusuf S, et al. Dabigatran versus warfarin in patients with atrial fibrillation. N Engl J Med. 2009;361:1139-51.

53. Hernandez I, Baik SH, Pinera A, et al. Risk of bleeding with dabigatran in atrial fibrillation. JAMA Intern Med. 2015;175:18-24.

54. Bengtson LG, Lutsey PL, Chen LY, MacLehose RF, Alonso A. Comparative effectiveness of dabigatran and rivaroxaban versus warfarin for the treatment of non-valvular atrial fibrillation. J Cardiol. 2017;69(6):868-876.

55. Korenstra J, Wijtvliet EP, Veeger NJ, et al. Effectiveness and safety of dabigatran versus 
acenocoumarol in 'real-world' patients with atrial fibrillation. Europace. 2016;18:1319-27.

56. Larsen TB, Rasmussen LH, Skjoth F, et al. Efficacy and safety of dabigatran etexilate and warfarin in "real-world" patients with atrial fibrillation: a prospective nationwide cohort study. J Am Coll Cardiol. 2013;61:2264-73.

57. Graham DJ, Reichman ME, Wernecke $M$, et al. Cardiovascular, bleeding, and mortality risks in elderly Medicare patients treated with dabigatran or warfarin for nonvalvular atrial fibrillation. Circulation. $2015 ; 131: 157-64$.

58. Labaf A, Carlwe M, Svensson PJ. Efficacy and safety of novel oral anticoagulants in clinical practice: a report from three centers in Sweden. Thromb J. 2014;12:29.

59. Lauffenburger JC, Farley JF, Gehi AK, et al. Effectiveness and safety of dabigatran and warfarin in real-world US patients with non-valvular atrial fibrillation: a retrospective cohort study. J Am Heart Assoc. 2015;4. doi:10.1161/JAHA.115.001798.

60. Romanelli RJ, Nolting L, Dolginsky M, et al. Dabigatran versus warfarin for atrial fibrillation in real-world clinical practice: a systematic review and meta-analysis. Circ Cardiovasc Qual Outcomes. 2016;9:126-34.

61. Potpara TS. Dabigatran in 'real-world' clinical practice for stroke prevention in patients with non-valvular atrial fibrillation. Thromb Haemost. 2015;114:1093-8.

62. Hijazi Z, Hohnloser SH, Oldgren J, et al. Efficacy and safety of dabigatran compared with warfarin in relation to baseline renal function in patients with atrial fibrillation: a RE-LY (randomized evaluation of long-term anticoagulation therapy) trial analysis. Circulation. 2014;129:961-70.

63. Kooiman J, van der Hulle T, Maas H, et al. Pharmacokinetics and pharmacodynamics of dabigatran $75 \mathrm{mg}$ b.i.d. in patients with severe chronic kidney disease. J Am Coll Cardiol. 2016;67:2442-4.

64. Chan KE, Edelman ER, Wenger JB, et al. Dabigatran and rivaroxaban use in atrial fibrillation patients on hemodialysis. Circulation. 2015;131:972-9.

65. Sharma M, Cornelius VR, Patel JP, et al. Efficacy and harms of direct oral anticoagulants in the elderly for stroke prevention in atrial fibrillation and secondary prevention of venous thromboembolism: systematic review and meta-analysis. Circulation. 2015;132:194-204.

66. Eikelboom JW, Wallentin L, Connolly SJ, et al. Risk of bleeding with 2 doses of dabigatran compared with warfarin in older and younger patients with atrial fibrillation: an analysis of the randomized evaluation of long-term anticoagulant therapy (RE-LY) trial. Circulation. 2011;123:2363-72.

67. Zhao Y, Hu ZY. Physiologically based pharmacokinetic modelling and in vivo [I]/K(i) accurately predict P-glycoprotein-mediated drug-drug interactions with dabigatran etexilate. $\mathrm{Br} \mathrm{J}$ Pharmacol. 2014;171:1043-53.

68. Zhang N, Liu XS, Li G, et al. Dabigatran-induced esophagitis: a frequently overlooked adverse effect. Int J Cardiol. 2016;212:358-9.

69. Artang R, Rome E, Nielsen JD, et al. Meta-analysis of randomized controlled trials on risk of myocardial infarction from the use of oral direct thrombin inhibitors. Am J Cardiol. 2013;112:1973-9.

70. Hohnloser SH, Lip GY. Dabigatran and myocardial infarction. Chest. 2015;147:e70-1.

71. Tornyos A, Kehl D, D'Ascenzo F, et al. Risk of myocardial infarction in patients with long-term non-vitamin $\mathrm{K}$ antagonist oral anticoagulant treatment. Prog Cardiovasc Dis. 2016;58:483-94.

72. Pollack CV Jr, Reilly PA, Eikelboom J, et al. Idarucizumab for dabigatran reversal. $\mathrm{N}$ Engl J Med. 2015;373:511-20.

73. Pollack CV Jr, Reilly PA, van Ryn J, et al. Idarucizumab for dabigatran reversal-full cohort analysis. N Engl J Med. 2017;377:431-41.

74. Laux V, Perzborn E, Kubitza D, et al. Preclinical and clinical characteristics of rivaroxaban: a novel, oral, direct factor Xa inhibitor. Semin Thromb Hemost. 2007;33:515-23.

75. Patel MR, Mahaffey KW, Garg J, et al. Rivaroxaban versus warfarin in nonvalvular atrial fibrillation. N Engl J Med. 2011;365:883-91.

76. Weinz C, Schwarz T, Kubitza D, et al. Metabolism and excretion of rivaroxaban, an oral, direct factor $\mathrm{Xa}$ inhibitor, in rats, dogs, and humans. Drug Metab Dispos. 2009;37:1056-64.

77. Heidbuchel $H$, Verhamme $P$, Alings $M$, et al. Updated European Heart Rhythm Association practical guide on the use of non-vitamin $\mathrm{K}$ antagonist anticoagulants in patients with non-valvular atrial fibrillation. Europace. 2015;17:1467-507.

78. Cohen D. Manufacturer failed to disclose faulty device in rivaroxaban trial. BMJ. 2016;354:i5131.

79. Rose M. ROCKET AF reanalysis reviews. Silver Spring: The Center for Drug Evaluation and Research. 2016. 
80. Camm AJ, Amarenco P, Haas S, et al. XANTUS: a real-world, prospective, observational study of patients treated with rivaroxaban for stroke prevention in atrial fibrillation. Eur Heart J. 2016;37:1145-53.

81. Beyer-Westendorf J, Camm AJ, Coleman CI, et al. Rivaroxaban real-world evidence: validating safety and effectiveness in clinical practice. Thromb Haemost. 2016;116:S13-23.

82. Coleman CI, Antz M, Bowrin K, et al. Real-world evidence of stroke prevention in patients with nonvalvular atrial fibrillation in the United States: the REVISIT-US study. Curr Med Res Opin. 2016;32:2047-53.

83. Noseworthy PA, Yao X, Abraham NS, et al. Direct comparison of dabigatran, rivaroxaban, and apixaban for effectiveness and safety in nonvalvular atrial fibrillation. Chest. 2016;150:1302-12.

84. Yao X, Abraham NS, Sangaralingham LR, et al. Effectiveness and safety of dabigatran, rivaroxaban, and apixaban versus warfarin in nonvalvular atrial fibrillation. J Am Heart Assoc. 2016;5. doi:10.1161/ JAHA.116.003725.

85. Lip GY, Keshishian A, Kamble S, et al. Real-world comparison of major bleeding risk among non-valvular atrial fibrillation patients initiated on apixaban, dabigatran, rivaroxaban, or warfarin. A propensity score matched analysis. Thromb Haemost. 2016;116:975-86.

86. Larsen TB, Skjoth F, Nielsen PB, et al. Comparative effectiveness and safety of non-vitamin $\mathrm{K}$ antagonist oral anticoagulants and warfarin in patients with atrial fibrillation: propensity weighted nationwide cohort study. BMJ. 2016;353:i3189.

87. McHorney CA, Peterson ED, Laliberte F, et al. Comparison of adherence to rivaroxaban versus apixaban among patients with atrial fibrillation. Clin Ther. 2016;38:2477-88.

88. Raparelli V, Proietti M, Cangemi R, Lip GY, Lane DA, Basili S. Adherence to oral anticoagulant therapy in patients with atrial fibrillation. Focus on non-vitamin $\mathrm{K}$ antagonist oral anticoagulants. Thromb Haemost. 2017;117(2):209-218.

89. Raghavan N, Frost CE, Yu Z, et al. Apixaban metabolism and pharmacokinetics after oral administration to humans. Drug Metab Dispos. 2009;37:74-81.

90. Connolly SJ, Eikelboom J, Joyner C, et al. Apixaban in patients with atrial fibrillation. $\mathrm{N}$ Engl J Med. 2011;364:806-17.
91. Granger CB, Alexander JH, McMurray JJ, et al. Apixaban versus warfarin in patients with atrial fibrillation. N Engl J Med. 2011;365:981-92.

92. Halvorsen S, Ghanima W, Fride Tvete I, et al. A nationwide registry study to compare bleeding rates in patients with atrial fibrillation being prescribed oral anticoagulants. Eur Heart J Cardiovasc Pharmacother. 2017;3(1):28-36.

93. Staerk L, Fosbol EL, Lip GY, et al. Ischaemic and haemorrhagic stroke associated with non-vitamin $\mathrm{K}$ antagonist oral anticoagulants and warfarin use in patients with atrial fibrillation: a nationwide cohort study. Eur Heart J. 2017;38(12):907-915.

94. Hijazi Z, Hohnloser SH, Andersson U, et al. Efficacy and safety of apixaban compared with warfarin in patients with atrial fibrillation in relation to renal function over time: insights from the ARISTOTLE randomized clinical trial. JAMA Cardiol. 2016;1:451-60.

95. Potpara TS, Lip GY. Drug-induced liver injury with oral anticoagulants: a threat or not? Heart. 2017;103:809-11.

96. Stollberger C, Finsterer J. Relevance of P-glycoprotein in stroke prevention with dabigatran, rivaroxaban, and apixaban. Herz. 2015;40(Suppl 2):140-5.

97. De Caterina R, Ageno W, Boriani G, et al. Edoxaban in atrial fibrillation and venous thromboembolism-ten key questions and answers: a practical guide. Adv Ther. 2017;34:620-37.

98. Weitz JI, Connolly SJ, Patel I, et al. Randomised, parallel-group, multicentre, multinational phase 2 study comparing edoxaban, an oral factor Xa inhibitor, with warfarin for stroke prevention in patients with atrial fibrillation. Thromb Haemost. 2010;104:633-41.

99. Mendell J, Zahir H, Matsushima N, et al. Drug-drug interaction studies of cardiovascular drugs involving P-glycoprotein, an efflux transporter, on the pharmacokinetics of edoxaban, an oral factor Xa inhibitor. Am J Cardiovasc Drugs. 2013;13:331-42.

100. Giugliano RP, Ruff CT, Braunwald E, et al. Edoxaban versus warfarin in patients with atrial fibrillation. N Engl J Med. 2013;369:2093-104.

101. FDA. FDA draft briefing document for the Cardiovascular and Renal Drugs Advisory Committee (CRDAC). meeting date: 30 Oct 2014. Silver Spring: FDA; 2014.

102. Pokorney SD, Shrader P, Thomas L, et al. Influence of kidney function estimation methods on eligibility for edoxaban population impact of the US Food 
and Drug Administration's approach for its product labeling. Circulation. 2016;134:1122-4.

103. Bohula EA, Giugliano RP, Ruff CT, et al. Impact of renal function on outcomes with edoxaban in the ENGAGE AF-TIMI 48 trial. Circulation. 2016;134:24-36.

104. Siegal DM, Curnutte JT, Connolly SJ, et al. Andexanet alfa for the reversal of factor Xa inhibitor activity. N Engl J Med. 2015;373:2413-24.

105. Connolly SJ, Milling TJ Jr, Eikelboom JW, et al. Andexanet alfa for acute major bleeding associated with factor $\mathrm{Xa}$ inhibitors. $\mathrm{N}$ Engl $\mathrm{J}$ Med. 2016;375:1131-41.

106. Bouillon K, Bertrand M, Maura G, et al. Risk of bleeding and arterial thromboembolism in patients with non-valvular atrial fibrillation either maintained on a vitamin $\mathrm{K}$ antagonist or switched to a non-vitamin K-antagonist oral anticoagulant: a retrospective, matched-cohort study. Lancet Haematol. 2015;2:e150-9.

107. De Caterina R, Husted S, Wallentin L, et al. Oral anticoagulants in coronary heart disease (Section IV). Position paper of the ESC Working Group on thrombosis-Task Force on Anticoagulants in Heart Disease. Thromb Haemost. 2016;115:685-711.

108. Vranckx P, Potpara T, Dagres N, et al. Non-vitamin $\mathrm{K}$ oral anticoagulants in patients with atrial fibrillation after cardiac surgery: the results of the European Heart Rhythm Association Survey. Europace. 2016;18:1113-6.

109. Frederiksen AS, Albertsen AE, Christesen AMS, Vinter N, Frost L, Møller DS. Cardioversion of atrial fibrillation in a real-world setting: non-vitamin $\mathrm{K}$ antagonist oral anticoagulants ensure a fast and safe strategy compared to warfarin. Europace. 2017. doi:10.1093/europace/eux188.

110. Wu S, Yang YM, Zhu J, et al. Meta-analysis of efficacy and safety of new oral anticoagulants compared with uninterrupted vitamin $\mathrm{K}$ antagonists in patients undergoing catheter ablation for atrial fibrillation. Am J Cardiol. 2016;117:926-34.

111. Vrijens B, Heidbuchel H. Non-vitamin K antagonist oral anticoagulants: considerations on once- vs. twice-daily regimens and their potential impact on medication adherence. Europace. 2015;17:514-23.

112. Sorensen R, Jamie Nielsen B, Langtved Pallisgaard J, Ji-Young Lee C, Torp-Pedersen C. Adherence with oral anticoagulation in non-valvular atrial fibrillation: a comparison of vitamin $\mathrm{K}$ antagonists and non-vitamin K antagonists. Eur Heart J Cardiovasc Pharmacother. 2017;3(3):151-6.
113. Camm AJ, Pinto FJ, Hankey GJ, et al. Non-vitamin K antagonist oral anticoagulants and atrial fibrillation guidelines in practice: barriers to and strategies for optimal implementation. Europace. 2015;17:1007-17.

114. Liberato NL, Marchetti M. Cost-effectiveness of non-vitamin $\mathrm{K}$ antagonist oral anticoagulants for stroke prevention in non-valvular atrial fibrillation: a systematic and qualitative review. Expert Rev Pharmacoecon Outcomes Res. 2016;16:221-35.

115. Huisman MV, Rothman KJ, Paquette M, et al. The changing landscape for stroke prevention in AF: findings from the GLORIA-AF registry phase 2. J Am Coll Cardiol. 2017;69:777-85.

116. Huisman MV, Ma CS, Diener HC, et al. Antithrombotic therapy use in patients with atrial fibrillation before the era of non-vitamin $\mathrm{K}$ antagonist oral anticoagulants: the Global Registry on Long-Term Oral Antithrombotic Treatment in Patients with Atrial Fibrillation (GLORIA-AF) Phase I cohort. Europace. 2016;18:1308-18.

117. Chan NC, Hirsh J, Ginsberg JS, et al. Betrixaban (PRT054021): pharmacology, dose selection and clinical studies. Future Cardiol. 2014;10:43-52.

118. Cohen AT, Harrington R, Goldhaber SZ, et al. The design and rationale for the acute medically ill venous thromboembolism prevention with extended duration betrixaban (APEX) study. Am Heart J. 2014;167:335-41.

119. Cohen AT, Harrington RA, Goldhaber SZ, et al. Extended thromboprophylaxis with betrixaban in acutely ill medical patients. $\mathrm{N}$ Engl J Med. 2016;375:534-44.

120. Gibson CM, Chi G, Halaby R, et al. Extended-duration betrixaban reduces the risk of stroke versus standard-dose enoxaparin among hospitalized medically ill patients: an APEX trial substudy (acute medically ill venous thromboembolism prevention with extended duration betrixaban). Circulation. 2017;135(7):648-655.

121. Eriksson BI, Dahl OE, Lassen MR, et al. Partial factor IXa inhibition with TTP889 for prevention of venous thromboembolism: an exploratory study. J Thromb Haemost. 2008;6:457-63.

122. Choi HY, Choi S, Kim YH, et al. Population pharmacokinetic and pharmacodynamic modeling analysis of GCC-4401C, a novel direct factor Xa inhibitor, in healthy volunteers. CPT Pharmacometrics Syst Pharmacol. 2016;5:532-43.

123. Johnson W. The left atrial appendage: our most lethal human attachment! Surgical implications. Eur J Cardiothorac Surg. 2000;17:718-22. 
124. Emmert MY, Puippe G, Baumuller S, et al. Safe, effective and durable epicardial left atrial appendage clip occlusion in patients with atrial fibrillation undergoing cardiac surgery: first long-term results from a prospective device trial. Eur J Cardiothorac Surg. 2014;45:126-31.

125. Lee R, Vassallo P, Kruse J, et al. A randomized, prospective pilot comparison of 3 atrial appendage elimination techniques: internal ligation, stapled excision, and surgical excision. J Thorac Cardiovasc Surg. 2016;152(4):1075-80.

126. Dagres N, Rolf S, Hindricks G. Percutaneous left atrial appendage suture ligation: not ready for prime time. J Am Coll Cardiol. 2014;64:573-5.

127. Healey JS, Crystal E, Lamy A, et al. Left atrial appendage occlusion study (LAAOS): results of a randomized controlled pilot study of left atrial appendage occlusion during coronary bypass surgery in patients at risk for stroke. Am Heart J. 2005;150:288-93.

128. Aryana A, Singh SK, Singh SM, et al. Association between incomplete surgical ligation of left atrial appendage and stroke and systemic embolization. Heart Rhythm. 2015;12:1431-7.

129. Katz ES, Tsiamtsiouris T, Applebaum RM, et al. Surgical left atrial appendage ligation is frequently incomplete: a transesophageal echocardiographic study. J Am Coll Cardiol. 2000;36:468-71.

130. Whitlock R, Healey J, Vincent J, et al. Rationale and design of the left atrial appendage occlusion study (LAAOS) III. Ann Cardiothorac Surg. 2014;3:45-54.

131. Ailawadi G, Gerdisch MW, Harvey RL, et al. Exclusion of the left atrial appendage with a novel device: early results of a multicenter trial. J Thorac Cardiovasc Surg. 2011;142:1002-9.e1.

132. Suwalski G, Emery R, Gryszko L, et al. Early operative comparison of two epicardial left atrial appendage occluding systems applied during off-pump coronary revascularisation in patients with persistent atrial fibrillation. Kardiochir Torakochirurgia Pol. 2016;13:10-4.

133. Brzezinski M, Bury K, Dabrowski L, et al. The new $3 \mathrm{D}$ printed left atrial appendage closure with a novel holdfast device: a pre-clinical feasibility animal study. PLoS One. 2016;11:e0154559.

134. Sievert H, Lesh MD, Trepels T, et al. Percutaneous left atrial appendage transcatheter occlusion to prevent stroke in high-risk patients with atrial fibrillation: early clinical experience. Circulation. 2002;105:1887-9.
135. Holmes DR, Reddy VY, Turi ZG, et al. Percutaneous closure of the left atrial appendage versus warfarin therapy for prevention of stroke in patients with atrial fibrillation: a randomised non-inferiority trial. Lancet. 2009;374:534-42.

136. Holmes DR Jr, Kar S, Price MJ, et al. Prospective randomized evaluation of the Watchman Left Atrial Appendage Closure device in patients with atrial fibrillation versus long-term warfarin therapy: the PREVAIL trial. J Am Coll Cardiol. 2014;64:1-12.

137. Reddy VY, Sievert H, Halperin J, et al. Percutaneous left atrial appendage closure vs warfarin for atrial fibrillation: a randomized clinical trial. JAMA. 2014;312:1988-98.

138. Holmes DR Jr, Doshi SK, Kar S, et al. Left atrial appendage closure as an alternative to warfarin for stroke prevention in atrial fibrillation: a patient-level meta-analysis. J Am Coll Cardiol. 2015;65:2614-23.

139. Tzikas A, Shakir S, Gafoor S, et al. Left atrial appendage occlusion for stroke prevention in atrial fibrillation: multicentre experience with the AMPLATZER Cardiac Plug. EuroIntervention. 2016;11:1170-9.

140. Freixa X, Chan JL, Tzikas A, et al. The Amplatzer Cardiac Plug 2 for left atrial appendage occlusion: novel features and first-in-man experience. EuroIntervention. 2013;8:1094-8.

141. Gloekler S, Shakir S, Doblies J, et al. Early results of first versus second generation Amplatzer occluders for left atrial appendage closure in patients with atrial fibrillation. Clin Res Cardiol. 2015;104:656-65.

142. Saw J, Lempereur M. Percutaneous left atrial appendage closure: procedural techniques and outcomes. JACC Cardiovasc Interv. 2014;7:1205-20.

143. Halkin A, Cohen C, Rosso R, et al. Left atrial appendage and pulmonary artery anatomic relationship by cardiac-gated computed tomography: implications for late pulmonary artery perforation by left atrial appendage closure devices. Heart Rhythm. 2016;13(10):2064-9.

144. Saw J, Fahmy P, Spencer R, et al. Comparing measurements of CT angiography, TEE, and fluoroscopy of the left atrial appendage for percutaneous closure. J Cardiovasc Electrophysiol. 2016;27:414-22.

145. Lip GY, Dagres N, Proclemer A, et al. Left atrial appendage occlusion for stroke prevention in atrial fibrillation in Europe: results of the European Heart Rhythm Association survey. Europace. 2013;15:141-3. 
146. Schmidt B, Chun KR. Antithrombotic therapy after left atrial appendage closure. Expert Rev Cardiovasc Ther. 2015;13:105-9.

147. Sharma D, Reddy VY, Sandri M, et al. Left atrial appendage closure in patients with contraindications to oral anticoagulation. J Am Coll Cardiol. 2016;67:2190-2.

148. Bartus K, Gafoor S, Tschopp D, et al. Left atrial appendage ligation with the next generation LARIAT(+) suture delivery device: early clinical experience. Int J Cardiol. 2016;215:244-7.

149. Price MJ, Gibson DN, Yakubov SJ, et al. Early safety and efficacy of percutaneous left atrial appendage suture ligation: results from the U.S. transcatheter LAA ligation consortium. J Am Coll Cardiol. 2014;64:565-72.

150. Ruff CT, Giugliano RP, Braunwald E, et al. Comparison of the efficacy and safety of new oral anticoagulants with warfarin in patients with atrial fibrillation: a meta-analysis of randomised trials. Lancet. 2014;383:955-62.

151. Boersma LV, Schmidt B, Betts TR, et al. Implant success and safety of left atrial appendage closure with the WATCHMAN device: peri-procedural outcomes from the EWOLUTION registry. Eur Heart J. 2016;37:2465-74.

152. Tzikas A, Holmes DR Jr, Gafoor S, et al. Percutaneous left atrial appendage occlusion: the Munich consensus document on definitions, endpoints, and data collection requirements for clinical studies. Europace. 2017;19:4-15.

153. Regazzoli D, Ancona F, Trevisi N, et al. Left atrial appendage: physiology, pathology, and role as a therapeutic target. Biomed Res Int. 2015;2015:205013.

154. Fanton Y, Robic B, Rummens JL, et al. Cardiac atrial appendage stem cells engraft and differentiate into cardiomyocytes in vivo: a new tool for cardiac repair after MI. Int J Cardiol. 2015;201:10-9.

155. Majunke N, Sandri M, Adams V, et al. Atrial and brain natriuretic peptide secretion after percutaneous closure of the left atrial appendage with the Watchman device. J Invasive Cardiol. 2015;27:448-52.

156. Kamohara K, Popovic ZB, Daimon M, et al. Impact of left atrial appendage exclusion on left atrial function. J Thorac Cardiovasc Surg. 2007;133:174-81.

157. Pellegrino PL, Fassini G, Dib M, et al. Left atrial appendage closure guided by $3 \mathrm{D}$ printed cardiac reconstruction: emerging directions and future trends. J Cardiovasc Electrophysiol. 2016;27:768-71.

158. Stampfuss J, Kubitza D, Becka M, et al. The effect of food on the absorption and pharmacokinetics of rivaroxaban. Int $\mathrm{J}$ Clin Pharmacol Ther. 2013;51:549-61.

159. National Center for Biotechnology Information. PubChem BioAssay Database. https://pubchem. ncbi.nlm.nih.gov/. Accessed 23 Nov 2016.

160. Boriani G, Pettorelli D. Atrial fibrillation burden and atrial fibrillation type: clinical significance and impact on the risk of stroke and decision making for long-term anticoagulation. Vasc Pharmacol. 2016;83:26-35. 